\title{
PAROTID DUCT CYST- OUR EXPERIENCE (IN A RURAL MEDICAL COLLEGE)
}

\author{
Subhendu Bikas Saha1, Purusottam Som², Debi Prassnna Ghosal ${ }^{3}$
}

${ }_{1}^{1}$ Associate Professor, Department of Surgery, Bankura Sammilani Medical College, Bankura, West Bengal, India.

${ }^{2}$ Assistant Professor, Department of Surgery, Bankura Sammilani Medical College, Bankura, West Bengal, India.

${ }^{3}$ Professor, Department of Surgery, Bankura Sammilani Medical College, Bankura, West Bengal, India.

\section{BACKGROUND}

ABSTRACT

Parotid duct sialocele is a rare entity. Patients presented with mostly painless, cystic swelling over the cheek encroaching to the parotid region. Diagnosis was done by FNAC and MR sialogram which revealed that the swellings were due to parotid duct sialocele. That swelling was due to obstruction to the parotid duct by sialolithiasis, trauma, etc. Some of those patients had h/o chewing of areca nuts and betel quid. We found in those cases oral submucosal fibrosis, but we did not find such association in any literature. Many treatment options available for e.g. repeated aspirations, marsupialisation etc. but mostly all were associated with recurrence. We found in literature that the foolproof treatment is superficial parotidectomy. In our cases also superficial parotidectomy was the best treatment option having no recurrence.

\section{MATERIALS AND METHODS}

We report twenty-two cases who presented with parotid duct sialocele to our OPD at BSMC, Bankura. We examined the cases and diagnosed those cases by several methods. We instituted several treatment options.

\section{RESULTS}

Initially we did aspiration in all patients with parotid duct sialocele, but out of the twenty-two cases recurrence occurred in twenty cases. The patients were disease free for 3-4 weeks. Next, we did repeated aspirations where seventeen cases came with recurrence. Then we opted for marsupialisation with biopsy. These marsupialised patients came back with recurrence after 4-5 months. Out of these seventeen cases, twelve cases were of oral submucosal fibrosis. All the cases with marsupialisation suffered from recurrence who ultimately undergwent superficial parotidectomy with no recurrence for 2-8 yrs.

\section{CONCLUSION}

Oral submucosal fibrosis may be one of causes for parotid duct sialocele which is seen in chronic betel quid and areca nuts chewers. Superficial parotidectomy is the definite treatment for parotid sialocele.

\section{KEY WORDS}

Parotid Duct, Sialocele, Submucosal Fibrosis, Betel Quid, Areca Nuts.

HOW TO CITE THIS ARTICLE: Saha SB, Som P, Ghosal DP. Parotid duct cyst- our experience. (In a rural medical college) J. Evolution Med. Dent. Sci. 2018;7(53):5610-5613, DOI: 10.14260/jemds/2018/1241

\section{BACKGROUND}

Stenson's duct sialectasia is an uncommon condition of the parotid gland which involves the dilation of the parotid duct, it is a chronic process and occurs most often secondary to obstruction to the duct which leads to accumulation of saliva and sub sequent dilation of the duct.(1) Non-neoplastic cyst are quite rare, and constitute approximately $2-5 \%$ of all salivary gland lesions.(2,3) Salivary duct cysts are true cysts that have a congenital or acquired origin but mostly acquired.(2) Although the exact causative factor is unknown, some suggestions include calculi, mucous plug, postoperative or post-inflammatory stricture.(3) The obstruction may be due to stenosis or stricture of the parotid duct due to several factors like Sialolithiasis or recent passage of stone or occult trauma of the duct, abnormal tooth or ill-fitting dentures, idiopathic. $(1,4)$

'Financial or Other Competing Interest': None.

Submission 17-11-2018, Peer Review 12-12-2018,

Acceptance 18-12-2018, Published 31-12-2018.

Corresponding Author:

Dr. Purusottam Som,

Doctor's Quarter,

G-6/34, Gobindanagar,

Bankura, West Bengal, India.

E-mail: purusom@yahoo.com

DOI: $10.14260 /$ jemds $/ 2018 / 1241$
Exposure to areca nut (Areca catechu) containing products with or without tobacco is currently believed to lead to OSF (Oral Submucous Fibrosis) in individuals with genetic immunologic or nutritional predisposition to the disease ${ }^{(5)}$ or from recurrent trauma from betel quid/betel nut chewing or due effects of arecoline leads to sub mucosal fibrosis. We found a quite number of cases of sialectasia of the parotid duct with oral submucosal fibrosis. Parotid duct sialectasia is characterised by an asymptomatic soft and mobile swelling on the parotid region.(6) It is soft, cystic and painless unless secondarily infected, $(2,6)$ The diagnosis is done by FNAC, ultrasonography and MR sialography. Both ultrasonography and MR sialography reveals that the gland proper remains nearly normal and only the ductular part is dilated. FNAC permits sampling and study of the fluid.(10) Many treatment modalities have been mentioned in the literature. Repeated aspiration and compression bandage or marsupialisation intra orally are the usual treatment.(1) Superficial parotidectomy with excision of duct along with sialocele has been the most preferred treatment in resistant cases where all conservative treatment fail.(4)

\section{MATERIALS \& METHODS}

We report (Cross Sectional Study) a series of 22 cases of Stenson duct sialocele, presented to this institution over a period of seven years (2007-2014). 
Initially we categorised the patients in two groups. In a first group (A) only the new cases, who did not take any treatment from anywhere for this specific problem (Denoted as our cases). In the second group (B) the old cases, who attended other institution and got treatment, but recurrence is there (Denoted outside old cases).

Epidemiological Pattern

\begin{tabular}{|c|c|}
\hline Group A & Group B \\
\hline Total Number of cases- 10 & Total Number of Cases case-12 \\
\hline Male-7 Female-3 & Male-6 Female-6 \\
\hline Average Age- 18-50 yrs. & Average Age- $18-50$ yrs. \\
\hline
\end{tabular}

\begin{tabular}{|c|c|c|}
\hline \multicolumn{3}{|c|}{ Associated Aetiological Factors } \\
\hline Tobacco \& Betel Chewer & 6 & 7 \\
\hline Poor Oral Hygiene & 4 & 5 \\
\hline
\end{tabular}

\section{RESULTS}

As per clinical presentation-

\section{Site}

Swelling over the cheek (Either left or right) over and in front of masseter.

\section{Size}

Ranging from $2 \mathrm{~cm}$ to $16 \mathrm{~cm}$.

\section{Symptom}

Cystic swelling with mild pain (10 cases). Only cystic swelling without pain 8 cases and 4 cases with severe pain (abscess).

\section{Investigation}

FNAC and Ultrasonography done to all cases and MR sialography in selected cases.

\section{Treatment}

\section{Stepwise Treatment given (Three Steps)-}

1. Aspiration (Maximum Three Times)

2. Intraoral marsupialisation.

3. Superficial parotidectomy with ductal exploration \& excision.

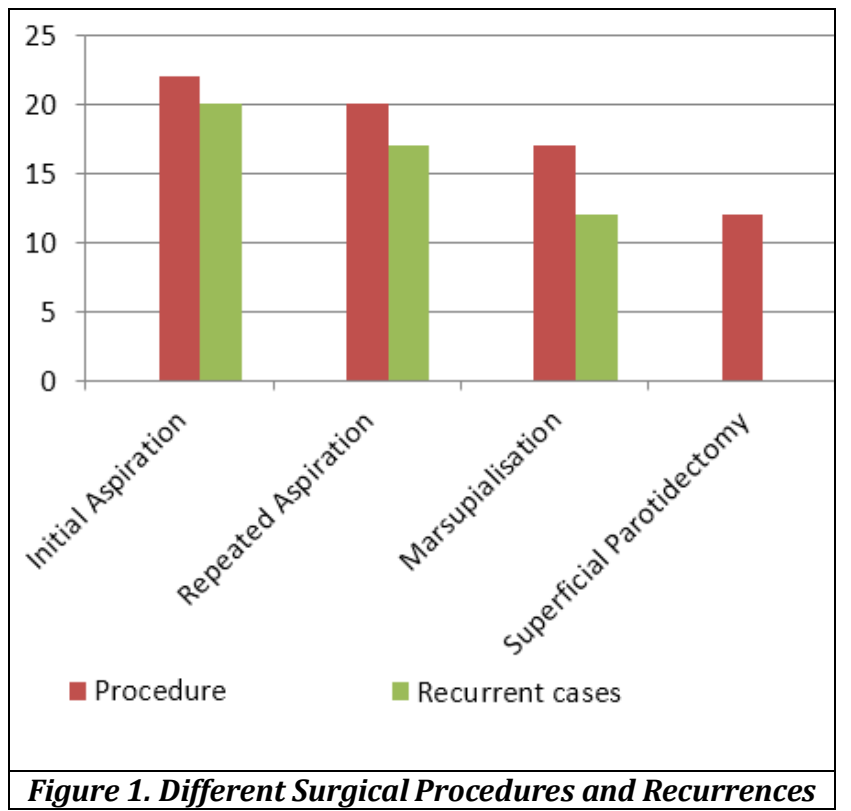

Different Procedure Performed

\begin{tabular}{|c|c|c|}
\hline Procedure & Group A & Group B \\
\hline Single Aspiration & 20 & 2 \\
\hline Multiple Aspiration & 17 & 3 \\
\hline Marsupialisation & 12 & 5 \\
\hline Superficial Parotidectomy & 12 & Nil \\
\hline
\end{tabular}

Abscess was treated with intraoral drainage.

Total number of cases in which biopsy was done while doing marsupialisation --- 17 cases.

In some cases of marsupialisation, the opening gets stenosed which is dilated daily with hard object like back of the tooth brush for better drainage of the cyst.

Total number of patients who habituated with uses of pan, gutka,

Total number of cases with submucosal fibrosis on biopsy report -12 .

Total number of cases, in which repeated aspiration failed - 17 cases.

Total number of cases recurred after marsupialisation all cases of marsupialisation. We did biopsy of the oral mucosa of the 17 cases while doing marsupialisation. Out of these 17 cases, in 12 cases the biopsy report was suggestive of submucosal fibrosis. So, we find strong association of parotid duct cyst with submucosal fibrosis.

Total number of cases in which parotid duct exploration \& excision with superficial parotidectomy done - in all cases recurred after marsupialisation.

Average interval of recurrence following marsupialisation 4-months.

After parotid duct exploration \& excision and superficial parotidectomy, all specimens sent for biopsy which reveals parotid duct sialectasis with normal parotid gland.

Post-operative recovery was uneventful in operated cases except facial nerve neuropraxia in two cases in the immediate post-operative period.

Long term follow-up- 2- 8 yrs. follow up done.

No. H/O recurrence after superficial parotidectomy.

\section{DISCUSSION}

Parotid duct cyst are mostly true cyst, it is also called retention cyst. There are two types of salivary gland cyst -the extravasation cyst (Without epithelial lining) and the retention cyst (With epithelial lining).(11) Extravasation cyst is also called pseudo cyst. The true cyst occurs due to chronic, complete or partial obstruction of the duct which leads to accumulation of secretion and dilation of the duct. This result in formation of an epithelial lined retention cyst or sialocele.(1,2) The obstruction of the duct may be due to several causes. Although the exact causative factor leading to obstruction is often unknown, some suggestions like sialolithiasis or recent passage of stone or occult trauma of the duct, abnormal tooth or ill-fitting dentures, idiopathic $(1,3,4)$ and poor oral hygiene.

There are some pseudo cysts also, which occurs due to duct transaction or duct disruption by trauma or by surgery. It causes leakage of glandular secretion and accumulation of it in the periductal area which causes an inflammatory reaction and result in a walled- off collection surrounded by granulation tissue and leads to formation of pseudo cyst.(1,2)

Here, we only dealt with the true cysts. But here, we concentrate our discussion of the obstruction of the duct by 
oral sub mucosal fibrosis which is a chronic debilitating disease of the oral cavity characterised by inflammation and the progressive fibrosis of the sub mucosal tissue.

Hard chewable substances mainly betel quid and areca nut or mixture of quid or chew in a combination of areca nut, betel leaf, slaked lime, tobacco leads to juxta epithelial inflammation followed by increased fibroblastic activity and formation of collagen fibres in the lamina propria of the oral mucous membrane(8) These collagen fibres are nondegradable and results in reduced phagocytic activity leads to submucosal fibrosis. (9)

This direct trauma to the oral mucosa by hard chewing of these substances and the effects of arecoline plays a major role in pathogenesis of oral submucosal fibrosis. $(2,10,12)$ Arecoline, an active alkaloid in betel nut stimulates fibroblast to increase collagen by $150 \%$.(8) Arecoline is found to elevate the mRNA and protein expression of Cystatin $\mathrm{C}$, a non glycosylated basic protein consistently upregulated in a variety fibrotic disease in a dose dependent manner in person with submucosal fibrosis. ${ }^{(8,9)}$

Diagnosis is based on clinical findings, location of the lesion, h/o trauma, poor oral hygiene, h/o chewing of betel quid (Betel leaf, areca nut, tobacco, slaked lime and catechu in various combination or all together).(8) Initial investigation was USG which detects the cystic nature of the content and also the relationship of the cystic lesion with the surroundings. Echogenic material inside denotes any pus. Any other abnormality in the parotid gland. Next investigation is FNAC which demonstrate the mucous retention phenomenon. The chemical analysis could disclose protein content and high amylase. The localisation and determination of the origin of the lesion can be done by computed tomography scanning and magnetic resonance imaging.(10) MRI has become an alternative non-invasive imaging technique for ductal salivary gland diseases. Conventional x-ray sialography used for investigating the ductal system of major salivary gland needs cannulation of the duct for installation of the contrast material and exposure to radiation. ${ }^{(13)}$

A variety of treatments have been suggested for sialocele. Conservative treatment of sialectasis - such as repeated aspiration, compression, dilation of papilla and stent placement-may not result in the successful resolution of this condition. Marsupialisation is a minimally invasive and reliable procedure for treating sialectasis.(1) The aspiration of the content and the compression dressing were capable to solve the case.(6) Superficial parotidectomy with excision of duct along with sialocele has been most preferred in resistant cases where all conservative treatment fail.(4) In search of the relevant literature does reveal a report of parotid duct cyst presented with a painless mass on right cheek undergone superficial parotidectomy which on histopathologic examination revealed main parotid duct cyst.(14) Another case report of painless preauricular mass on the right side, in which superficial parotidectomy was performed which on histopathologic examination revealed parotid duct cyst.

We dealt with 22 cases of parotid duct sialocele over a period of 6 years. Sialectasis of the parotid duct was diagnosed by clinical examination and confirmation by aspiration, ultrasonography and sialography. Aspiration reveals clear viscid fluid which was sent for biochemical analysis which revealed high amylase content (Ranging from 7000-10000 units/L). Sialography helps in delineation of the sialocele cavity. Ultrasonography helped us to detect any solid component or any echogenic purulent material within the sialocele cavity. We did biopsy of the oral mucosa of the 17 cases while doing marsupialisation. Out of these 17 cases, in 12 cases the biopsy report was suggestive of submucosal fibrosis. So, we find strong association of parotid duct cyst with submucosal fibrosis.

\section{CONCLUSION}

After a through search for any association of parotid duct sialocele with oral submucosal fibrosis, no association was found in literatures. But we found a strong association of parotid duct sialocele with oral submucosal fibrosis and also superficial parotidectomy with excision of the duct to be the definitive treatment for parotid duct sialocele.

\section{REFERENCES}

[1] Lohia S, Joshi AS. Ideopathic sialectesis of the Stensen's duct treated with marsupialisation. BMJ Case Rep 2013;2013. pii: bcr 2013201548.

[2] Dadaci M, Tuncbilek G, Ince B, et al. Parotid duct cyst in a child. Indian Journal of Plastic Surgery 2015;48(1):92-3.

[3] Vinayachandran D, Sankarapandian S. Salivary duct cyst: histopathologic correlation. J Clin Imaging Sci 2013;3(Suppl 1):3. doi:10.4103/2156-7514.111236.

[4] Dalal S, Manjul M, Garg P, et al. Stensen's Duct Sialocele: a potentially morbid clinical condition. The Internet Journal of Otolaryngology 2008;11(1).

[5] Donoghue M, Basandi PS, Adarsh H, et al. Habitassociated $\mathrm{pH}$ changes in oral submucous fibrosis - a controlled cross-sectional study. J Oral Maxillofac Pathol 2015;19(2):175-81. www.jomfp.in.

[6] De Araujo MR, Centurion BS, De Albuquerque DF, et al. Management of a parotid sialocele in a young patient: case report and literature review. J Appl Oral Sci 2010;18(4):432-6.

[7] Edkins 0, Van Lierop AC, Fagan JJ, et al. Peroral drainage of post-traumatic sialocoeles: report of three cases. The Journal of Laryngeology \& Otology 2009;123(8):922-4.

[8] Lountzis NI, James WD. Oral submucous fibrosis. Updated: Jan 2012. http://emedicine.medscape.com/article/1077241

[9] Khan S, Chatra L, Prashant SK, et al. Pathogenesis of oral submucous fibrosis. J Cancer Res Ther 2012;8(2):199-203.

[10] Nallasivam KU, Sudha BR. Oral mucocele: review of literature and a case report. Journal of Pharmacy and Bioallied Sciences 2015;7(Suppl 2):S731-3.

[11] Chaves FN, Carvalho FSR, Pereira KMA, et al. Salivary duct cyst in the upper lip: case report and review of the literature. Indian Journal of Pathology and Microbiology 2013;56(2):163-5.

[12] Erkan AN, Harcan C, Bal N, et al. Parotid duct cyst: a case report. B-ENT 2006;2(3):117-9. 
[13] Kalinowski M, Heverhagen JT, Rehberg E, et al. Comparative study of MR sialography and digital subtraction sialography for benign salivary gland disorders. AJNR Am J Neuroradiol 2002;23(9):148592.
[14] Feng AJ, Xiao WL, Zhao BD, et al. Parotid major duct cyst: a case report. Shanghai Journal of Stomatology (Shanghai Kou Qiang Yi Xue) 2011;20(3):334-6. 